\title{
In Vivo and In Vitro Nitinol Corrosion Properties
}

\author{
Melissa K. Lonn ${ }^{1} \cdot$ Justin M. Metcalf ${ }^{2} \cdot$ Brian D. Choules ${ }^{2}$
}

Published online: 25 September 2015

(C) The Author(s) 2015. This article is published with open access at Springerlink.com

\begin{abstract}
Regulatory authorities often require in vitro testing on medical devices prior to approval. Current standardized corrosion testing methods (ASTM F2129) require testing in a non-physiologic, de-oxygenated solution for a pre-exposure time of $\leq 1 \mathrm{~h}$; however, no correlations between the prescribed simulated environment and whole blood conditions have been elucidated. This study compared open circuit potential (OCP), breakdown potentials $\left(\mathrm{E}_{\mathrm{b}}\right), \mathrm{E}_{\mathrm{b}}-\mathrm{OCP}$, and cyclic polarization curves tested in vivo (OCP only) and in vitro in whole blood to those tested in phosphate-buffered saline (PBS). Two oxide thicknesses of Nitinol, two solution oxygen contents (deaerated and aerated solutions), and two pre-exposure durations (acute and chronic) were investigated. The in vitro OCP in whole blood was not significantly different than the in vivo OCP, suggesting that whole blood in vitro can be used to determine baseline corrosion behavior of medical implants. $\mathrm{E}_{\mathrm{b}}$ - OCP tested per ASTM F2129 was comparable to acute whole blood and was conservative compared to chronic whole blood for both oxide thicknesses. However, OCP, $\mathrm{E}_{\mathrm{b}}$, and cyclic polarization curves were not always comparable to whole blood. Testing in aerated PBS achieved $\mathrm{E}_{\mathrm{b}}, \mathrm{E}_{\mathrm{b}}-\mathrm{OCP}$, and cyclic polarization curves that were comparable to or more
\end{abstract}

This article is an invited paper selected from presentations at the International Conference on Shape Memory and Superelastic Technologies 2014, held May 12-16, 2014, in Pacific Grove, California, and has been expanded from the original presentation.

Melissa K. Lonn

mlonn@medinst.com

1 Cook Research Incorporated, 1 Geddes Way, West Lafayette, IN 47906, USA

2 MED Institute, Inc., West Lafayette, IN, USA conservative than whole blood testing, regardless of preexposure duration and oxide thickness.

Keywords NiTi $<$ materials - Shape memory stents . Corrosion · In vivo - Open circuit potential - Breakdown potential

\section{Introduction}

In vitro testing is essential for gaining insight into the performance of medical devices. Ideally, in vitro tests closely represent the clinical performance of the device. However, a poorly designed test may cause many hours of unnecessary design iterations, testing, and regulatory activities in an effort to interpret results which do not adequately mimic clinical performance.

It is imperative to fully understand how in vitro results correlate to in vivo results. Designing in vitro tests to mimic chronic physiologic conditions is necessary, and often the tests need to be run in a short amount of time. However, interpretation of short-term results to predict chronic conditions can be difficult. ASTM F2129 is a well accepted in vitro corrosion test for metallic implants that describes a $1-2 \mathrm{~h}$ test in a deaerated solution to assess chronic corrosion resistance [1]; however, defining a clinically relevant acceptance criterion has proven difficult and controversial [2]. A clinically relevant acceptance criterion for Nitinol (NiTi) is especially important, since there are multitudes of ways to prepare the surface, which can dramatically affect the ASTM F2129 results.

To develop a clinically relevant acceptance criterion, the open circuit potential (OCP or the rest potential) of the sample in vivo must be understood. Several in vivo studies have been performed on $\mathrm{NiTi}[3,4]$; however, the reported 
range of NiTi rest potentials was quite large $\left(-330 \mathrm{mV}_{\mathrm{SCE}}\right.$ to $+10 \mathrm{mV}_{\mathrm{SCE}}$ ), and the results were not directly compared to in vitro results.

It has been previously recommended to set an acceptance criterion without consideration of the test sample OCP $[5,6]$. Specifically, it has been recommend that $\mathrm{E}_{\mathrm{b}}<300 \mathrm{mV}$ is unacceptable, $\mathrm{E}_{\mathrm{b}}$ between 300 and $600 \mathrm{mV}$ is marginal, and $\mathrm{E}_{\mathrm{b}}>600 \mathrm{mV}$ is acceptable. It is important to note that these recommendations were made with consideration of only a few metallic alloys (316 stainless steel, cobalt chromium, titanium, and Nitinol). The application of an absolute acceptance criterion for breakdown potential is problematic, since the OCP is different for various metals and metallic surface finishes, and varies with implant duration. Therefore, due to the wide variety of OCPs, an absolute acceptance criterion related to breakdown alone might not be appropriate for the medical device industry.

An alternative to using absolute $\mathrm{E}_{\mathrm{b}}$ as the acceptance criterion is to evaluate the corrosion resistance using the difference between breakdown and the open circuit potential $\left(\mathrm{E}_{\mathrm{b}}-\mathrm{OCP}\right)$, which has been recommended previously [7-9]. This difference provides more information about the device's corrosion behavior and how much the device OCP is able to deviate without inducing localized corrosion (i.e., pitting and breakdown). The argument against $E_{b}-E_{r}$ (where ASTM F2129 defines $E_{r}$, rest potential, as the OCP following $\leq 1 \mathrm{~h}$ deaerated pre-exposure) has been that $E_{r}$ is measured in a non-physiologic solution that is not representative of in vivo OCP. In vivo OCP values are not well known, and can vary based on immersion solution, oxygen content, immersion time, and surface finish. Several studies have been performed to understand how oxygen content and immersion time affect OCP, $\mathrm{E}_{\mathrm{b}}$, and $\mathrm{E}_{\mathrm{b}}$ - OCP [7, 8]; however, no direct correlation with in vivo results has been reported.

Therefore, the aim of this study was to compare the corrosion results of two different NiTi oxide thicknesses tested in vivo (measuring short-term OCP only) and in vitro in whole blood to the results in phosphate-buffered saline (PBS). Additionally, this study investigated the effect of oxygen content of the test solution and pre-exposure time on $\mathrm{OCP}, \mathrm{E}_{\mathrm{b}}$, and $\mathrm{E}_{\mathrm{b}}-\mathrm{OCP}$.

\section{Materials and Methods}

Testing was conducted on two NiTi oxide thicknesses used for medical devices: black oxide (BO), and electropolished and passivated (EP). These surface finishes were chosen to encompass the range of oxide thicknesses typically used for NiTi medical devices. NiTi \#1 (Fort Wayne Metals, Fort Wayne, IN) with a black oxide finish was acquired in the straight annealed condition, with a diameter of $0.026^{\prime \prime}$. NiTi \#1 is better than or equal to the chemical composition defined by ASTM F2063. The BO oxide thickness was measured to be $670 \AA$ Asing Auger electron spectroscopy (Fig. 1a). For the EP processing, BO NiTi samples from the same lot were electropolished and passivated. To illustrate changes in breakdown potential due to testing environment and pre-exposure time, a suboptimal electropolish exhibiting occasional breakdown was chosen for EP so that breakdown would occur in a portion of samples prior to $\mathrm{E}_{\mathrm{v}}$. The resulting oxide thickness was measured to be $34 \AA$ (Fig. 1b). All samples were rinsed with distilled water (ASTM Type 1) and alcohol, and then dried prior to sending to Evans Analytical Group (EAG) for Auger testing and analysis.

Electrochemical corrosion testing was performed with Gamry Reference 600 potentiostats. All potentials were measured in reference to saturated calomel electrodes (SCE). Gamry DC105 software was used to perform the test.

BO and EP NiTi wires were tested in 4 different environments: (1) in vivo arterial blood, (2) in vitro venous whole blood, (3) in vitro aerated PBS, and (4) in vitro deaerated PBS.

\section{In Vivo Studies}

For the in vivo studies, an ovine model was used. Anesthesia was induced, and heparin was administered between 100-200 IU/kg. Testing was approved under facility approved IACUC. Exposed wire $\left(2.1 \mathrm{~cm}^{2}\right)$ was placed within the animal, while the remainder of the wire was masked off with a non-conductive resin (Miccrostop). The wire was inserted through an 18 French sheath placed within the aorta via femoral access. Bilateral femoral arteries were accessed, allowing two wires to be tested simultaneously. An elongated SCE was also placed within the 18 French sheath, parallel to the test specimen. The tip of the elongated SCE was placed near the wire, outside the sheath. Placement was verified via fluoroscopy. The potential difference between the elongated SCE and the inhouse standard SCE was verified to be within $\pm 3 \mathrm{mV}$. Bilateral BO and EP wires were tested, and the access location was alternated with each new sample to eliminate the potential variable effects of test location and animal. The potential after $1 \mathrm{~h}$ was recorded as the OCP. Arterial blood chemistries including $\mathrm{pH}$, partial pressure of oxygen $\left(\mathrm{pO}_{2}\right)$, saturation of oxygen $\left(\mathrm{sO}_{2}\right)$, hemoglobin $(\mathrm{Hb})$, ionic calcium concentration (iCa), chlorine concentration $(\mathrm{Cl})$, sodium concentration $(\mathrm{Na})$, and potassium concentration (K) were measured before and after each open circuit scan using an Abaxis i-Stat blood analyzer (cartridges CHEM8+ and CG4+). 


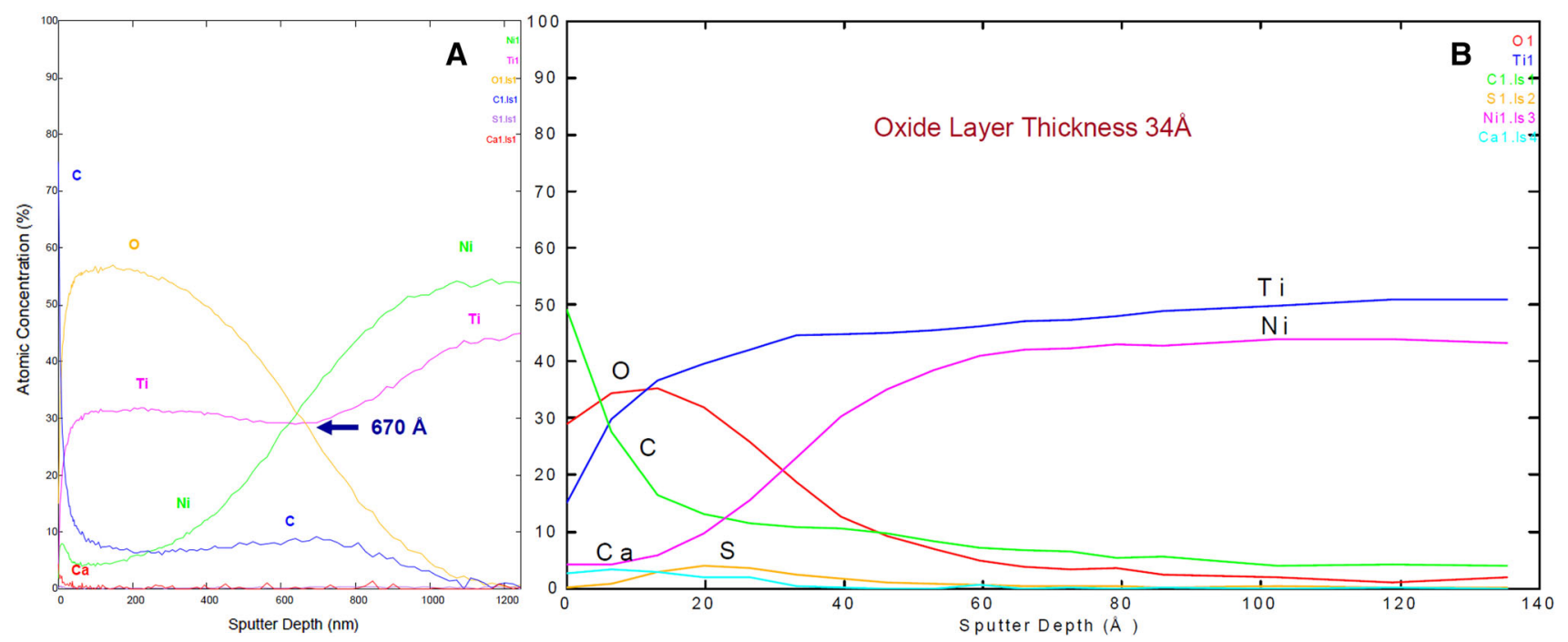

Fig. 1 Auger analysis of BO (a) and EP (b) oxide thicknesses resulting in thicknesses of $670 \AA$ and $34 \AA$, respectively

\section{In Vitro Studies}

Samples were placed within a $1 \mathrm{~L}$ jacketed electrochemical corrosion cell containing whole blood, deaerated PBS, or aerated PBS. Samples were electrically connected to stainless steel mandrels using a silver solder epoxy. Miccrostop was applied to the sample/mandrel interface and the cut ends of the sample. The exposed surface area of the wire samples was $1.6 \mathrm{~cm}^{2}$. Heparinized bovine whole blood (LAMPIRE Biological Laboratories, Inc., Pipersville, PA) with $1 \mathrm{X}$ penicillin/streptomycin was used to prevent bacterial growth. Ionic concentrations were measured from each blood lot. Oxygen concentration, oxygen saturation, and $\mathrm{pH}$ were measured before and after each test and daily blood exchanges. PBS [1] was either deaerated (bubbled with nitrogen) or aerated (bubbled with compressed laboratory air) and buffered to a $\mathrm{pH}$ of $7.4 \pm 0.2$. Test solutions were maintained at $37^{\circ} \mathrm{C} \pm$ $1{ }^{\circ} \mathrm{C}$. Open circuits (or pre-exposures) were measured for either $1 \mathrm{~h}$ (acute) or $200 \mathrm{~h}$ (chronic), which were monitored discretely for a minimum of $1 \mathrm{~h}$ each day until the end of the test. NiTi OCP has been reported to reach steady

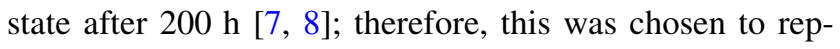
resent a chronic state. Table 1 shows the sample sizes for each OCP test group.

For all in vitro studies, a cyclic polarization scan was conducted following the open circuit (pre-exposure) delay. Cyclic polarization testing followed ASTM F2129, except for the experimental changes to the aeration and open circuit duration. The forward and reverse scan rates were $1 \mathrm{mV} / \mathrm{s}$. The cyclic polarization scan was started at the OCP, and the $\mathrm{E}_{\mathrm{v}}$ (vertex potential) was $1200 \mathrm{mV}$. Pitting of the samples was confirmed using light microscopy of up to $\times 25$ magnification.
Pre-exposure solution, pre-exposure time, and scan solution were investigated; specifically, samples were assigned to eight different cyclic polarization experimental groups (Table 2). Group 1 (acute) samples and Group 2 (chronic) samples were tested in heparinized bovine whole blood. The natural oxygen content in the whole blood was desired, eliminating the need to bubble the solution. Group 3 (acute) samples and Group 4 (chronic) samples were tested in aerated PBS. Additionally, Group 5 (acute) and Group 6 (chronic) samples were used to investigate the effect of pre-exposure in aerated PBS prior to testing in deaerated PBS, in which case the solution was deaerated for $30 \mathrm{~min}$ with nitrogen prior to the scan. Finally, Group 7 (acute - the control group tested fully to ASTM F2129) and Group 8 (chronic) samples were tested in deaerated PBS.

\section{Data Analysis}

Experimental groups were compared using the GLM procedure in SAS (Statistical Analysis Software, version 9.3) with a least-square mean statement utilizing Tukey test $(\alpha=0.05)$. For groups with censored data (i.e., lack of breakdown prior to reversing the scan), a Kaplan-Meier survival curve (lifetest procedure in SAS) was used to compare groups.

\section{Results}

\section{Acute and Chronic Open Circuit Potential (OCP)}

OCP following $1 \mathrm{~h}$ pre-exposure (acute) in solution for all test environments is presented in Fig. 2. The OCP for acute in vitro whole blood was not significantly different from 
Table 1 Open circuit experimental groups

\begin{tabular}{llll}
\hline Surface finish & Solution & \multicolumn{2}{l}{ Number of samples tested } \\
\cline { 3 - 4 } & & 1 h open circuit & 200 h open circuit \\
\hline BO NiTi & In vivo whole blood & 8 & N/A \\
& In vitro whole blood & 12 & 4 \\
& In vitro aerated PBS & 32 & 16 \\
& In vitro deaerated PBS & 16 & 8 \\
EP NiTi & In vivo whole blood & 8 & N/A \\
& In vitro whole blood & 12 & 4 \\
& In vitro aerated PBS & 40 & 16 \\
& In vitro deaerated PBS & 28 & 16 \\
\hline
\end{tabular}

Table 2 Cyclic polarization experimental groups

\begin{tabular}{|c|c|c|c|c|c|}
\hline \multirow{2}{*}{$\begin{array}{l}\text { Cyclic polarization } \\
\text { experimental group }\end{array}$} & \multicolumn{2}{|l|}{ Open circuit (OC) } & \multirow[t]{2}{*}{ Polarization scan solution } & \multicolumn{2}{|c|}{ Sample size } \\
\hline & Solution & Duration $(\mathrm{h})$ & & BO NiTi & EP NiTi \\
\hline 1 & In vitro whole blood & 1 & In vitro whole blood & 8 & 8 \\
\hline 2 & & 200 & & 4 & 4 \\
\hline 3 & In vitro aerated PBS & 1 & In vitro aerated PBS & 8 & 11 \\
\hline 4 & & 200 & & 8 & 7 \\
\hline 5 & In vitro aerated PBS & 1 & In vitro deaerated PBS & 8 & 11 \\
\hline 6 & & 200 & & 8 & 8 \\
\hline 7 (control) & In vitro deaerated PBS & 1 & In vitro deaerated PBS & 8 & 11 \\
\hline 8 & & 200 & & 7 & 7 \\
\hline
\end{tabular}

the OCP for in vivo whole blood for both oxide thicknesses ( $p=0.0636$ for BO, 0.9964 for EP). For the acute BO groups, in vitro aerated and deaerated PBS were significantly different from the whole blood groups ( $p<0.0001)$. For the acute EP groups, only the aerated PBS group was significantly different from the whole blood groups $(p<0.0001)$. Oxygen content influenced mean OCP for all samples at $1 \mathrm{~h}$ (Fig. 3), though the effect was greater on samples with thicker oxides. Therefore, depending on the

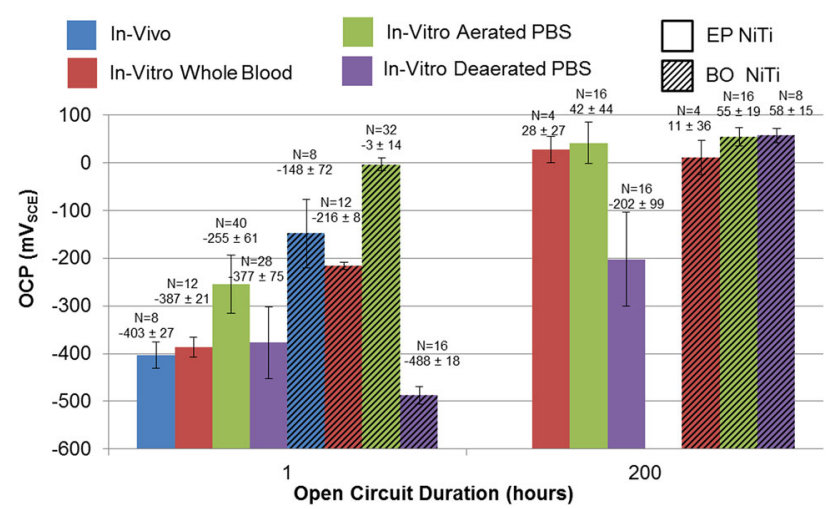

Fig. 2 Acute and chronic open circuit potentials oxide thickness, testing in conditions performed per ASTM F2129 (deaerated PBS for $1 \mathrm{~h}$ ) might result in OCPs which are not representative of in vivo OCPs.

OCPs after $200 \mathrm{~h}$ (chronic) compared to $1 \mathrm{~h}$ (acute) OCPs are shown in Fig. 2. All potentials increased with longer pre-exposure times, and all groups, except EP in deaerated PBS, trended toward a similar potential (11-58 mV). Therefore, even after $200 \mathrm{~h}$, deaerated OCPs were not representative of in vivo potentials for all oxide

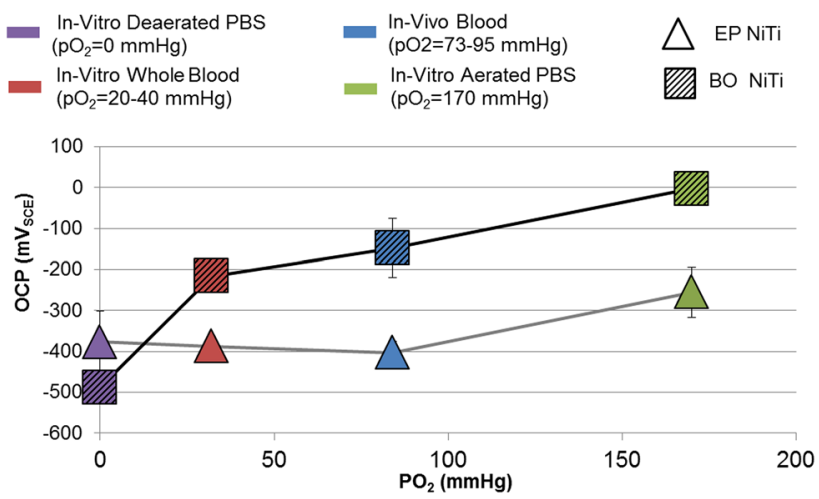

Fig. 3 Open circuit potential versus oxygen partial pressure 


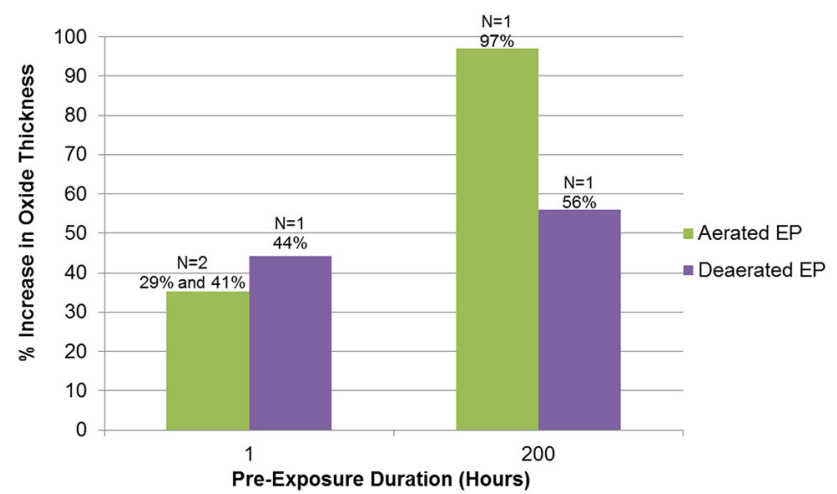

Fig. 4 Percent increase in oxide thickness versus pre-exposure duration of EP NiTi wires

thicknesses, whereas chronic-aerated OCPs were similar to chronic whole blood OCPs for both oxide thicknesses $(p=0.9976$ and $p=0.7397)$.
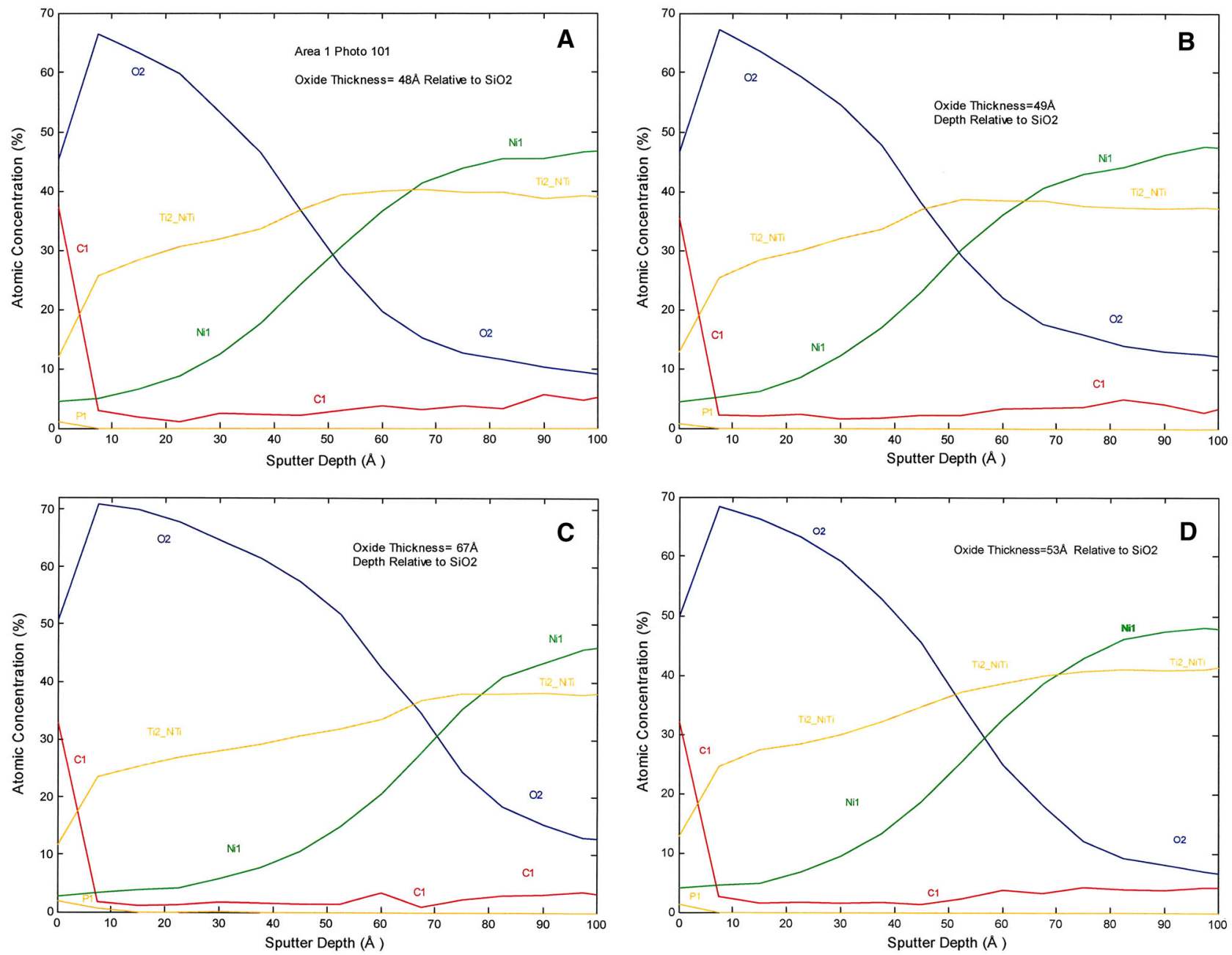

Fig. 5 Auger analysis of EP oxide thicknesses following pre-exposure: acute aerated (a); acute deaerated (b); chronic aerated (c); chronic deaerated (d) 
Survival Distribution Function

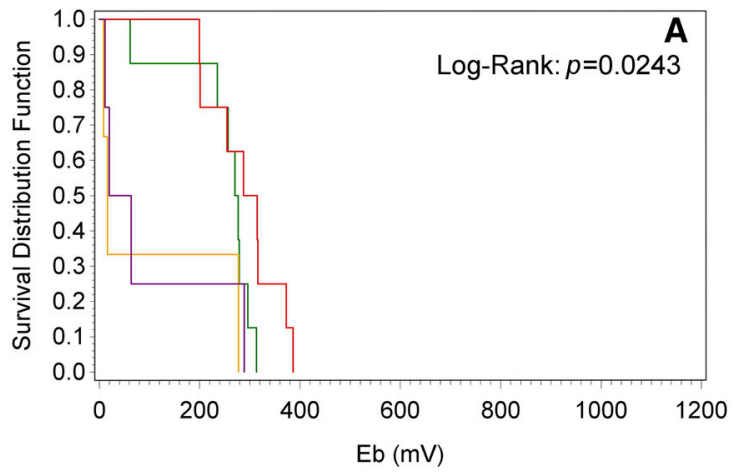

Test Condition:

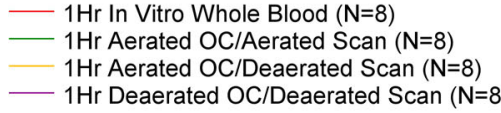

Survival Distribution Function

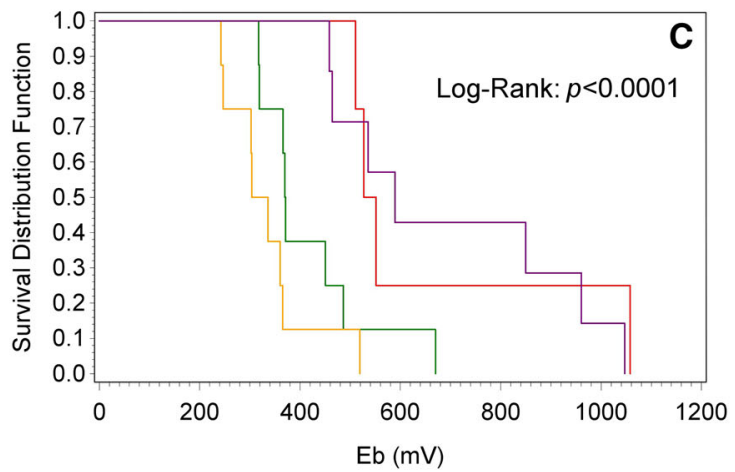

Test Condition:

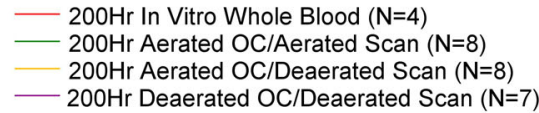

Survival Distribution Function
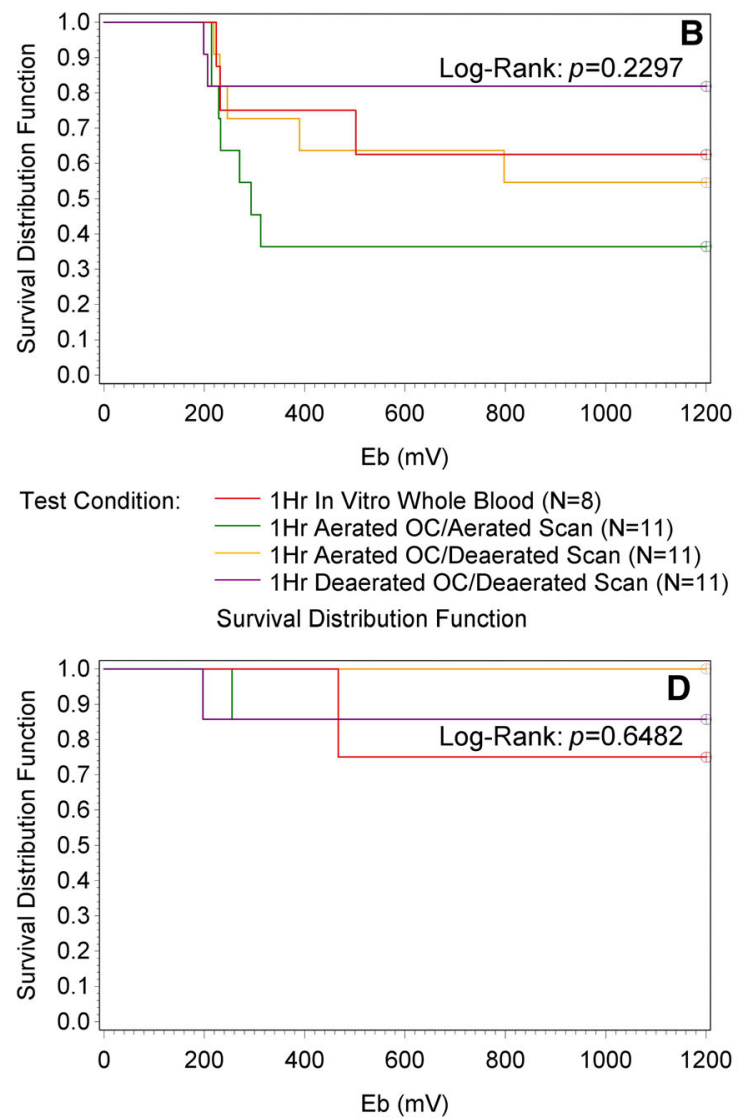

$\begin{array}{ll}\text { Test Condition: } & -200 \mathrm{Hr} \text { In Vitro Whole Blood }(\mathrm{N}=4) \\ & -200 \mathrm{Hr} \text { Aerated OC/Aerated } \mathrm{Scan}(\mathrm{N}=7) \\ & 200 \mathrm{Hr} \text { Aerated OC/Deaerated } \mathrm{Scan}(\mathrm{N}=8) \\ & 200 \mathrm{Hr} \text { Deaerated OC/Deaerated Scan }(\mathrm{N}=7)\end{array}$

Fig. 6 Kaplan-Meier curves for $\mathrm{E}_{\mathrm{b}}$ : acute BO (a); acute EP (b); chronic BO (c); chronic EP (d)

most similar to whole blood $(p=0.7774)$ (Figs. 6a and $7 \mathrm{a})$. The $\mathrm{E}_{\mathrm{b}}$ of chronic BO samples exposed exclusively to deaerated solutions (pre-exposure and scan) and the samples exposed exclusively to aerated solutions were most similar to the whole blood $\mathrm{E}_{\mathrm{b}}(p=0.9850$ and $p=0.1439$, respectively) (Fig. 6c). Most importantly, the $\mathrm{E}_{\mathrm{b}}$ occurring after chronic immersion in whole blood was significantly different than the control as tested per ASTM F2129 (1 h deaerated pre-exposure with deaerated scan), $p<0.0001$. For both acute and chronic EP experimental groups, no significant difference in $\mathrm{E}_{\mathrm{b}}$ was observed for the different testing conditions ( $p=0.2297$ and $p=0.6482$, respectively). However, acute EP samples exposed exclusively to aerated solutions had the most conservative (i.e., resulting in the lowest $E_{b}$ ) breakdown survival curve (Fig. 6b). Overall, fewer EP samples broke down after chronic preexposure compared to acute pre-exposure (Fig. 6b and d).

It is also interesting to note that acute BO samples preexposed to aerated solutions followed by a deaerated scan were not significantly different than the samples exposed exclusively to deaerated solutions ( $p=0.9957$, Figs. 6a and $7 \mathrm{a}$ ), whereas chronic BO samples pre-exposed to aerated solutions followed by a deaerated scan were similar to the samples exposed exclusively to aerated solutions $(p=0.7786$, Figs. 6c and 7c).

\section{Difference Between $E_{b}$ and OCP $\left(E_{b}-O C P\right)$}

For both oxide thicknesses, $\mathrm{E}_{\mathrm{b}}-\mathrm{OCP}$ increased with preexposure duration, Fig. 8. For Groups 5 and 6, OCPs were taken after the aerated pre-exposure, prior to deaerating with nitrogen to start the cyclic polarization scan.

The BO samples exposed exclusively to aerated solutions were more conservative (i.e., resulting in a lower $\mathrm{E}_{\mathrm{b}}$ - OCP) than whole blood for both acute and chronic time points (Fig. 8a and c). The $\mathrm{E}_{\mathrm{b}}-\mathrm{OCP}$ results for $\mathrm{BO}$ samples exposed only to deaerated solutions were most similar to whole blood for both acute and chronic durations (Fig. 8a and c). However, acute cyclic polarization scans for deaerated PBS and whole blood were noticeably 

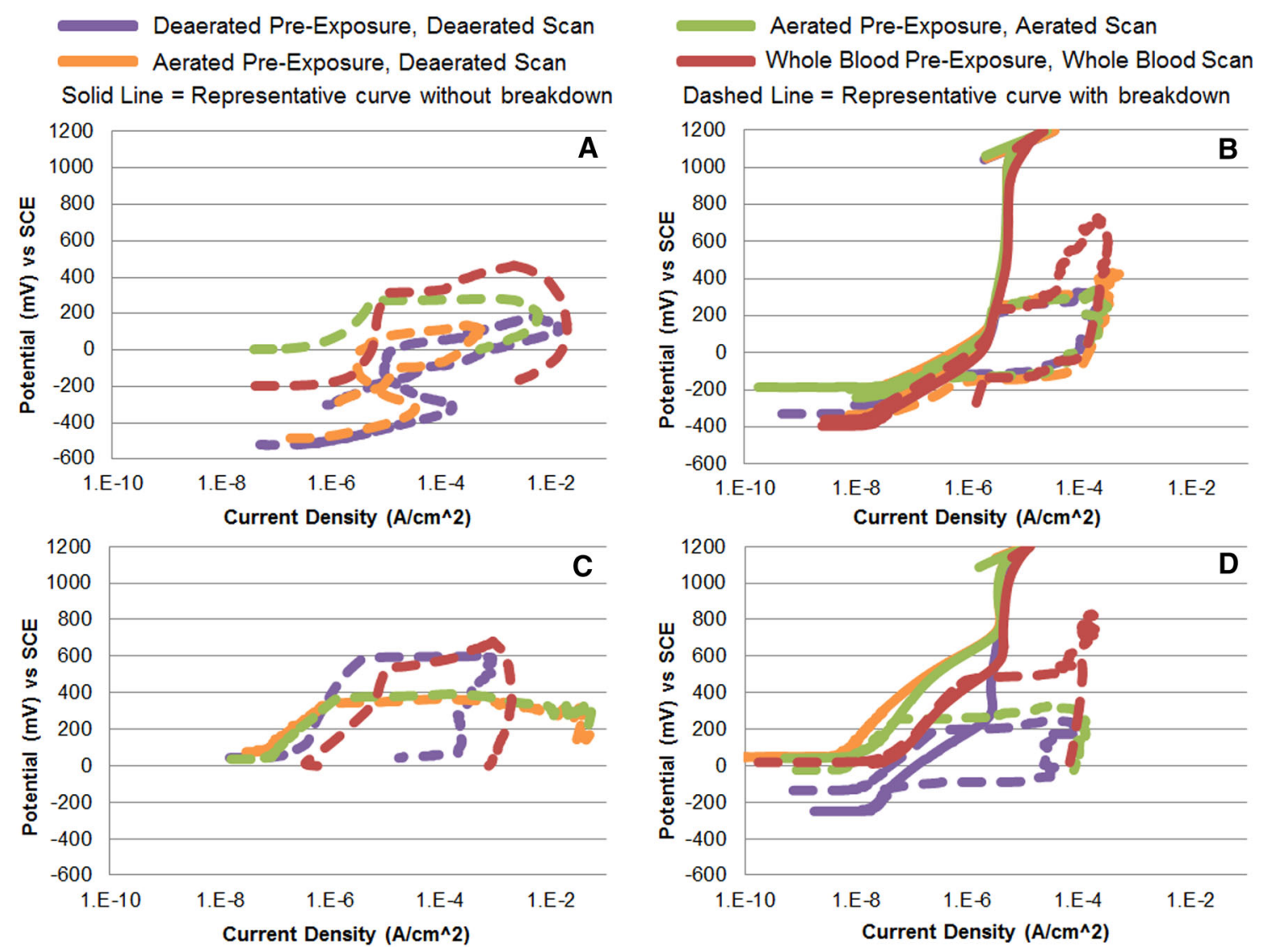

Fig. 7 Representative cyclic polarization curves: acute BO (a); acute EP (b); chronic BO (c); chronic EP (d)

different (Fig. 7a). Thus, in vivo conditions are not fully represented with a $1 \mathrm{~h}$ deaerated pre-exposure with deaerated scan, depending on oxide thickness.

For both acute and chronic EP experimental groups, no significant difference between the potential difference survival curves was observed for the different testing conditions ( $p=0.0580$ and $p=0.6482$, respectively). The most conservative condition for acute EP $\mathrm{E}_{\mathrm{b}}-\mathrm{OCP}$ was the aerated pre-exposure with an aerated scan.

A summary of results is presented in Table 3.

\section{Discussion}

The cyclic polarization testing standard for metallic devices (ASTM F2129) has been well received by regulatory agencies as an acceptable test for corrosion resistance for implant devices [1]. However, determination of an acceptance criterion has been a topic of much debate. The standard states that the method is intentionally severe and meant for comparison purposes only; however, an absolute acceptance criterion for $\mathrm{E}_{\mathrm{b}}$ has been proposed $[5,6]$. The standard defines a pre-exposure time $\leq 1 \mathrm{~h}$; however, oxide thicknesses have been found to change over time [10, 11], which can potentially change the corrosion resistance. Therefore, care must be taken when determining clinically relevant acceptance criteria. Additionally, the standard dictates that testing be conducted in a non-physiological de-oxygenated solution, with the aim of producing a lower $E_{b}$. However, blood and other body fluids are not anoxic (typical arterial and venous oxygen partial pressure ranges are $80-100$ and $40-50 \mathrm{mmHg}$, respectively) [12]. Finally, the corrosion standard for galvanic testing of medical implants, ASTM F3044, states that testing should be performed in an aerated solution and that the coupled potential be compared to $E_{b}$ as found in ASTM F2129; thus, further confounding testing practices when comparing aerated galvanic results to deaerated breakdown results [13].

Therefore, this study investigated the effect of oxygen content and pre-exposure time on OCP, $\mathrm{E}_{\mathrm{b}}$, and $\mathrm{E}_{\mathrm{b}}-\mathrm{OCP}$ for two different NiTi oxide thicknesses (BO and EP). Both $\mathrm{EP}$ and BO samples were investigated since medical devices with EP and BO oxide thicknesses are currently available in the market. By analyzing two extremes in oxide thicknesses, a better understanding of how test conditions affect corrosion results for a broad range of NiTi medical devices can be achieved. Samples were tested in vivo (acute OCP only) and in vitro in whole blood to 
Survival Distribution Function

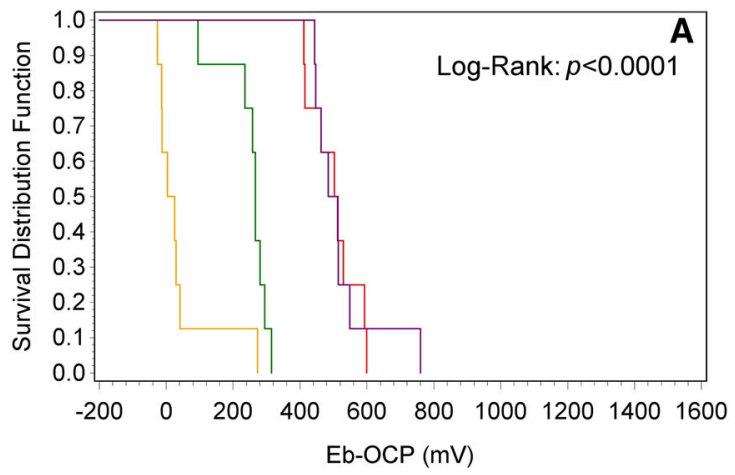

Test Condition:

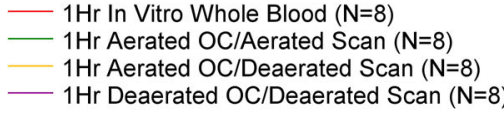

Survival Distribution Function

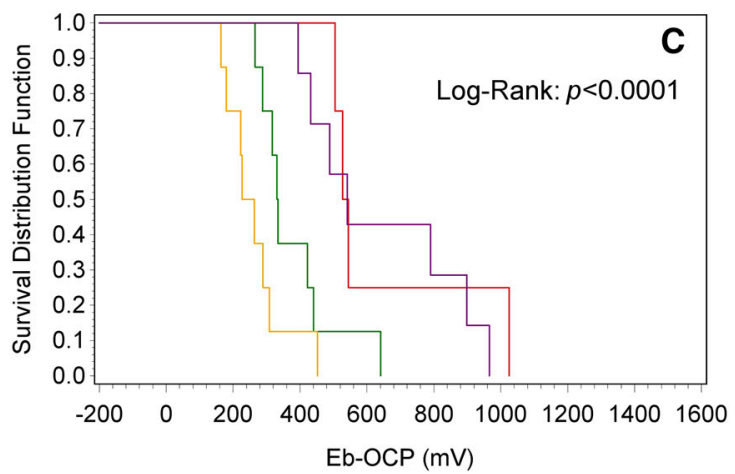

Test Condition:

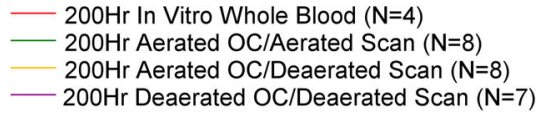

Survival Distribution Function

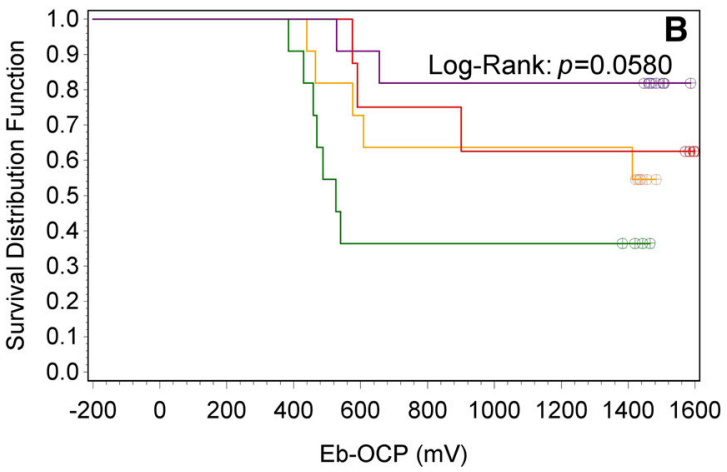
Test Condition: - $1 \mathrm{Hr}$ In Vitro Whole Blood $(\mathrm{N}=8)$ - $1 \mathrm{Hr}$ Aerated OC/Aerated Scan ( $\mathrm{N}=11)$ - $1 \mathrm{Hr}$ Aerated OC/Deaerated Scan ( $\mathrm{N}=11)$ - $1 \mathrm{Hr}$ Deaerated OC/Deaerated Scan $(\mathrm{N}=11)$ Survival Distribution Function

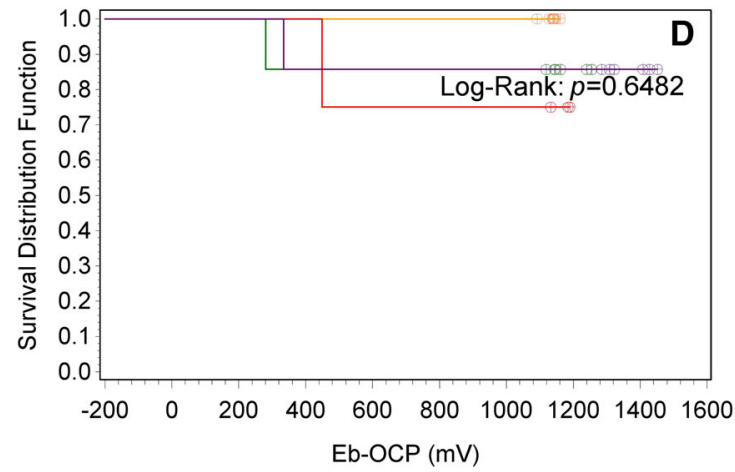

$\begin{array}{ll}\text { Test Condition: } & -200 \mathrm{Hr} \text { In Vitro Whole Blood }(\mathrm{N}=4) \\ & -200 \mathrm{Hr} \text { Aerated OC/Aerated } \mathrm{Scan}(\mathrm{N}=7) \\ & 200 \mathrm{Hr} \text { Aerated OC/Deaerated Scan }(\mathrm{N}=8) \\ & 200 \mathrm{Hr} \text { Deaerated OC/Deaerated Scan }(\mathrm{N}=7)\end{array}$

Fig. 8 Kaplan-Meier curves for $\mathrm{E}_{\mathrm{b}}-$ OCP: acute BO (a); acute EP (b); chronic BO (c); chronic EP (d)

generate baseline physiologic results to compare against simulated fluid (aerated and deaerated PBS) results.

This study showed that both oxygen content and preexposure time had a significant effect on the corrosion behavior of NiTi, regardless of oxide thickness. Performing testing in vivo allows full understanding of the physiologic corrosion behavior. In this study, in vitro and in vivo whole blood resulted in similar OCP. Although not investigated in this study, it is expected that in vitro $E_{b}$ and cyclic polarization curves in whole blood would be similar to that occurring in vivo. However, testing in whole blood alone is undesirable, due to the number of samples needed to establish reliability and the increased cost of testing. This study determined that $1 \mathrm{~h}$ data in whole blood were more conservative (i.e., lower $\mathrm{E}_{\mathrm{b}}-\mathrm{OCP}$ ) than chronic data for both $\mathrm{BO}$ and EP. Therefore, a reasonable compromise might be to test a small sample size in whole blood for $1 \mathrm{~h}$ to gain an understanding of the representative physiologic corrosion behavior of the implant and compare those results to larger scale testing performed in a simulated solution.

Previous investigators have shown that $\mathrm{E}_{\mathrm{b}}-\mathrm{OCP}$ remained constant or increased with time, suggesting that $1 \mathrm{~h}$ pre-exposure time was conservative [8]. This is in agreement with the results obtained in this study. OCP, $\mathrm{E}_{\mathrm{b}}$, and $E_{b}-$ OCP improved with time for both oxide thicknesses and aerations.

For deaerated PBS testing conditions, $\mathrm{E}_{\mathrm{b}}-\mathrm{OCP}$ was comparable to whole blood for both oxide thicknesses and pre-exposure times. However, the actual values of $\mathrm{OCP}, \mathrm{E}_{\mathrm{b}}$, and the cyclic polarization curves were not always similar to those obtained in whole blood. In fact, the chronic EP OCP for deaerated PBS remained $\sim 200 \mathrm{mV}$ more active than whole blood, and the acute $\mathrm{BO} \mathrm{E}_{\mathrm{b}}$ for deaerated PBS was found to be $\sim 250 \mathrm{mV}$ more negative than whole blood. Additionally, the cyclic polarization curves for acute deaerated pre-exposure were very different than the curves tested in whole blood, depending on the oxide thickness. The 
Table 3 Summary of results

\begin{tabular}{|c|c|}
\hline Result & Figure \\
\hline \multicolumn{2}{|l|}{ Open circuit potentials $(O C P)$} \\
\hline $\begin{array}{l}\text { In vitro whole blood OCP was not significantly different than in vivo OCP for both oxide thicknesses } \\
(p=0.0636 \text { and } p=0.9964)\end{array}$ & Figure 2 \\
\hline $\begin{array}{l}\text { Control (ASTM F2129) OCP was significantly different than in vivo OCP, depending on oxide thickness } \\
(p<0.0001 \text { for BO) }\end{array}$ & Figure 2 \\
\hline All OCPs increased over time & Figure 2 \\
\hline $\begin{array}{l}\text { Chronic deaerated PBS samples were significantly different than chronic whole blood, depending on the oxide } \\
\text { thickness }(p<0.0001 \text { for EP) }\end{array}$ & Figure 2 \\
\hline $\begin{array}{l}\text { Chronic-aerated PBS samples were not significantly different than chronic whole blood regardless of the oxide } \\
\text { thickness }(p=0.9976 \text { and } p=0.7397)\end{array}$ & Figure 2 \\
\hline \multicolumn{2}{|l|}{ Breakdown potentials $\left(E_{b}\right)$} \\
\hline All $E_{b}$ improved over pre-exposure time & Figure 6 \\
\hline $\begin{array}{l}\mathrm{E}_{\mathrm{b}} \text { tested per ASTM F2129 were significantly different than } \mathrm{E}_{\mathrm{b}} \text { chronically submerged in whole blood depending } \\
\text { on oxide thickness }(p<0.0001 \text { for BO) }\end{array}$ & Figures 6 and 7 \\
\hline $\begin{array}{l}\text { Aerated } \mathrm{E}_{\mathrm{b}} \leq \text { whole blood } \mathrm{E}_{\mathrm{b}} \text { for both oxide thicknesses and pre-exposure times, and had similar cyclic } \\
\text { polarization curves }\end{array}$ & Figures 6 and 7 \\
\hline \multicolumn{2}{|l|}{ Difference in $E_{b}-O C P$} \\
\hline All $E_{b}-$ OCP values improved over pre-exposure time & Figure 8 \\
\hline $\begin{array}{l}\text { Acute pre-exposure to aerated PBS prior to testing in deaerated PBS resulted in negative } E_{b}-\text { OCP values with } \\
\text { no pitting observed during open circuit }\end{array}$ & Figures 8 and 9 \\
\hline $\begin{array}{l}\text { Deaerated PBS and whole blood were comparable and the least conservative (i.e., the highest difference between } \\
\mathrm{E}_{\mathrm{b}} \text { and } \mathrm{OCP} \text { ) test conditions regardless of pre-exposure time and oxide thickness. However acute cyclic } \\
\text { polarization curves in deaerated PBS and whole blood were different, depending on oxide thickness }\end{array}$ & Figures 7 and 8 \\
\hline $\begin{array}{l}\text { Aerated PBS was more conservative (i.e., the lower difference between } \mathrm{E}_{\mathrm{b}} \text { and } \mathrm{OCP} \text { ) than or comparable to } \\
\text { whole blood regardless of pre-exposure time and oxide thickness }\end{array}$ & Figure 8 \\
\hline
\end{tabular}

acute deaerated BO samples exhibited a passivation potential where no such behavior was observed in whole blood. Therefore, testing in a deaerated environment may not fully capture the physiologic corrosion behavior of the sample in a physiologically relevant environment.

Aerated pre-exposure prior to performing the cyclic polarization scan in a deaerated environment has been recommended previously and resulted in an increased OCP and a more conservative $\mathrm{E}_{\mathrm{b}}$ - OCP than testing with a deaerated pre-exposure [7]. Similarly, an increase in OCP and a conservative $\mathrm{E}_{\mathrm{b}}$ - OCP with aerated pre-exposure followed by a deaerated scan were observed in this study. However, acute aerated pre-exposure was not sufficient to prevent the OCP from immediately becoming more active during the deaeration of the solution with nitrogen (Fig. 9a), resulting in a polarization scan starting at a more negative potential than the recorded aerated OCP. This resulted in an extremely conservative $E_{b}-$ OCP value, in which some values were negative (though corrosion was not observed during the open circuit). Therefore, testing in a deaerated environment following $1 \mathrm{~h}$ of aerated pre-exposure produces potentially misleading results. It was found that $200 \mathrm{~h}$ of pre-exposure in an aerated solution was sufficient to reach a steady state such that the OCP was not influenced when nitrogen was introduced (Fig. 9b).
Furthermore, chronic-aerated pre-exposure followed by a deaerated scan achieved a representative OCP and a conservative $E_{b}$, resulting in a conservative $E_{b}-O C P$ compared to whole blood ( $390 \mathrm{mV}$ difference for BO). Therefore, a chronic pre-exposure in an aerated environment prior to a deaerated scan is a conservative testing option; however, it is essential that the OCP reaches a steady state.

Samples were also evaluated in an aerated environment following an aerated pre-exposure. For both oxide thicknesses, acute-aerated OCPs were most comparable to chronic physiologic OCP values. For both time points and oxide thicknesses, aerated cyclic polarization curves and $E_{b}$ were similar to whole blood. Additionally, aerated $\mathrm{E}_{\mathrm{b}}-$ OCP was less than or equal to whole blood for both time points and oxide thicknesses. Overall, corrosion properties (OCP, $\mathrm{E}_{\mathrm{b}}$, and $\mathrm{E}_{\mathrm{b}}-\mathrm{OCP}$ ) increased with time, indicating that acute aerated testing is conservative compared to chronic pre-exposure durations. However, increasing the pre-exposure duration might be a useful option for determining actual chronic corrosion properties. Additionally, testing in an aerated environment allows for a direct comparison to galvanic testing per ASTM F3044 [13]. Regardless of pre-exposure duration, testing in an aerated environment following an aerated pre-exposure is a viable and conservative option for 

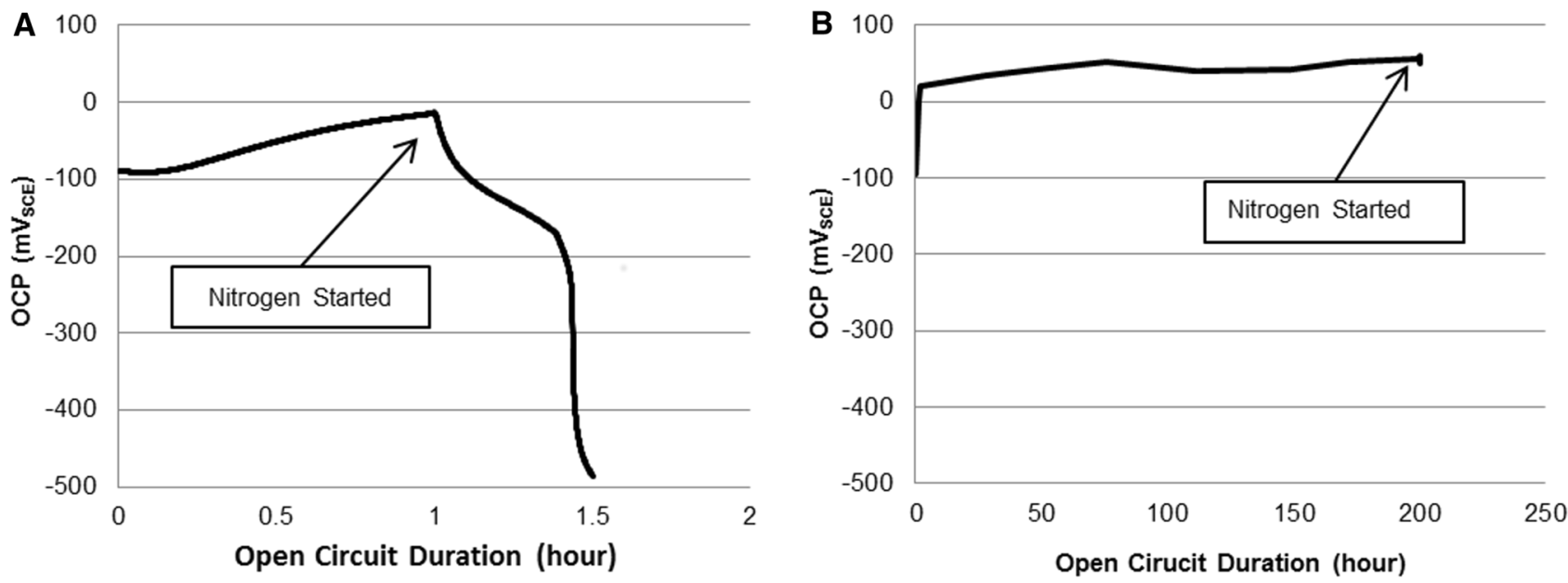

Fig. 9 BO pre-exposure: $1 \mathrm{~h}$ aerated followed by $30 \mathrm{~min}$ deaeration with nitrogen (a), $200 \mathrm{~h}$ aerated followed by 30 min deaeration with nitrogen $(\mathbf{b})$

determining the physiologic corrosion behavior of NiTi implants used for medical devices.

\section{Conclusions}

Whole blood can be used to perform in vitro testing to determine baseline corrosion behavior of medical implants and aid in acceptance criterion development. $\mathrm{E}_{\mathrm{b}}-\mathrm{OCP}$ tested according to the conditions defined in ASTM F2129 was comparable to acute whole blood and is conservative compared to chronic whole blood for both oxide thicknesses of NiTi. However, testing per the conditions in ASTM F2129 resulted in OCP, $\mathrm{E}_{\mathrm{b}}$, and cyclic polarization curves that were not always comparable to whole blood depending on oxide thickness. A standardized corrosion assessment method should not be dependent on metallic surface finish. Pre-exposing and conducting the polarization scan in aerated PBS achieved $\mathrm{E}_{\mathrm{b}}, \mathrm{E}_{\mathrm{b}}-\mathrm{OCP}$, and cyclic polarization curves that were comparable to or more conservative than whole blood testing, regardless of preexposure duration and oxide thickness. Testing in aerated PBS also allows direct comparison to coupled galvanic potentials measured using the methods in ASTM F3044. Thus, testing in aerated PBS provides a more conservative and complete assessment of corrosion resistance of metallic medical implants.

Acknowledgments The authors would like to thank Sara Sherman, Jacqueline Garrison, and Scott Snyder of Cook Research Incorporated and William Voorhees, III of MED Institute, Inc. for their critical review of the manuscript. Additionally, the authors would like to thank Bret Teany and Alan Saunders of Cook Research Incorporated for their help in figure formatting. The authors would also like to thank the members of the Non-Clinical Testing teams at Cook Research Incorporated who supported the in vivo and in vitro testing.
Finally, the authors would like to acknowledge Evans Analytical Group (www.eag.com) for conducting the Auger analysis.

Open Access This article is distributed under the terms of the Creative Commons Attribution 4.0 International License (http://crea tivecommons.org/licenses/by/4.0/), which permits unrestricted use, distribution, and reproduction in any medium, provided you give appropriate credit to the original author(s) and the source, provide a link to the Creative Commons license, and indicate if changes were made.

\section{References}

1. ASTM-F2129 (2008) Standard test method for conducting cyclic potentiodynamic polarization measurements to determine the corrosion susceptibility of small implant devices. ASTM International, West Conshohocken

2. Takai E (2012) Cardiovascular metallic implants: corrosion, surface characterization, and nickel leaching. FDA CDRH, p 36-78

3. Pértile LB, Silva P, Peccin VB, Peres R, Silveira PG, Giacomelli C, Giacomelli FC, Fredel MC, Spinelli A (2009) In vivo human electrochemical properties of a NiTi-based alloy (Nitinol) used for minimally invasive implants. J Biomed Mater Res Part A 89:1072-1078

4. Shih C-C, Lin S-J, Chung K-H, Chen Y-L, Su Y-Y (2000) Increased corrosion resistance of stent materials by converting current surface film of polycrystalline oxide into amorphous oxide. J Biomed Mater Res 52:323-332

5. Rosenbloom SN, Corbett R (2007) An assessment of ASTM F2129 electrochemical testing of small medical implants-lessons learned. Proceedings of the NACE Corrosion Conference \& Exposition, Nashville, TN, USA, p 11-15

6. Corbett RA (2004) Laboratory corrosion testing of medical implants. Proceedings of Materials and Processes for Medical Devices Conference, $\mathrm{p}$ 166-171

7. Eiselstein L, Steffey D, Nissan A, Corlett N, Dugnani R, Kus E, Stewart S (2009) Acceptance criteria for corrosion resistance of medical devices: statistical analysis of nitinol pitting in in vivo environments. J Mater Eng Perform 18:768-780

8. Warner CP (2009) The effect of exposure to simulated body fluids on breakdown potentials. J Mater Eng Perform 18:754-759 
9. Pound BG (2006) Susceptibility of nitinol to localized corrosion. J Biomed Mater Res Part A 77:185-191

10. Rondelli G, Torricelli P, Fini M, Rimondini L, Giardino R (2006) In vitro corrosion study by EIS of an equiatomic NiTi alloy and an implant quality AISI 316 stainless steel. J Biomed Mater Res B Appl Biomater 79:320-324

11. Istephanous N, Bai Z, Gilbert J, Rohly K, Belu A, Trausch I, Untereker D (2003) Oxide films on metallic biomaterials: myths, facts and opportunities. MSF 426:3157-3164
12. Guyton AC (2006) Textbook of medical physiology, Eleventh edn. Elsevier Health Sciences, Philadelphia

13. ASTM-F3044 (2014) Test method for standard test method for evaluating the potential for galvanic corrosion for medical implants. ASTM International, West Conshohocken 